\title{
Effect of physical exercise on pain thresholds and plasma beta-endorphins in patients with silent and symptomatic myocardial ischaemia
}

\author{
C. Droste, H. Meyer-Blankenburg, M. W. GreenleE* and H. Roskamm
}

Rehabilitationszentrum für Herz- und Kreislaufkranke, 7812 Bad Krozingen, and *Neurologische Universitätsklinik, Abt. Neurophysiologie 7800 Freiburg, F.R.G.

KEY WORDS: Silent myocardial ischaemia, endorphins, naloxone, experimental pain measurement, physical exercise.

In a double-blind study, eight patients with stmptomatic myocardial ischaemia and nine with astmptomatic myocardial ischaemia were compared during physical exercise under naloxone (6 mg i.v.) or placebo. Plasma beta-endorphin, cortisol and catecholamines were measured before exercise, during maximal exercise, and 10, 20 and 60 min after exercise. A tourniquet pain test (on the forearm, under control of transcutaneous $\mathrm{PO}_{2}$ ), and an electrical pain test (intracutaneous electrode placed in the finger with the electrical stimulus under computer control and two-interval forced-choice psychophysical technique) were performed before exercise as well as immediately after, and 60 min after exercise. Plasma beta-endorphin levels increased significantly $(\mathrm{P}<0.01)$ during exercise in symptomatic and asymptomatic patient groups: every patient showed an increase on betaendorphins during and after exercise. However, the increase found in beta-endorphins during and after exercise was significantly larger $(\mathrm{P}<0.01)$ in asymptomatic than in symptomatic patients. After naloxone, this difference was no longer evident. Angina pectoris during exercise was reported with less latency in symptomatic patients $(\mathrm{P}<0.05)$ and occurred in two of nine asymptomatic pattents following naloxone. The time course of plasma cortisol levels exhibited the same pattern as beta-endorphins with the same significant differences between symptomatic and asymptomatic groups. Electrical pain thresholds, though on average higher in asymptomatic patients (2.21 mA vs. $0.79 \mathrm{~mA})$, were not affected by exercise or naloxone. Asymptomatic patients required more time to reach pain thresholds in the tourniquet pain test $(\mathrm{P}<0.02)$. After exercise, tourniquet pain thresholds were significantly lower $(\mathrm{P}<0.01)$ under naloxone compared with placebo. The results suggest that there are quantitative differences in the endorphinergic regulation of pain in patients with symptomatic and asymptomatic myocardial ischaemia.

\section{Introduction}

In pain research it is widely accepted that an endogenous pain control system exists in man, which indicates a low resting level, but with adequate stimuli (such as pain itself, injury or stress) can be phasically activated ${ }^{[1,2]}$. Research in sports medicine has indicated that pronounced physical exercise may be a stimulus that can activate this system. Several investigations $^{[3-5]}$ have indicated that severe physical exercise can elicit elevations in pain thresholds that are evident up to $1-2 \mathrm{~h}$ after exercise. A temporary hypoalgesia has been found in the rat after exercise $^{[6]}$. It has been proposed that changes in endogenous opiate levels may be responsible for this phasic hypoalgesia, although a direct relationship

Address for correspondence C. Droste M.D. Ph.D Rehabilitationszentrum für Herz und Kreislaufkranke. Südrung 15, D-7812 Bad Kronzingen. F R.G. between plasma beta-endorphin levels and pain thresholds appears unlikely ${ }^{[7]}$. Exercise-induced elevations in pain thresholds can be reversed by naloxone $e^{[4.5 .8 .9]}$, further suggesting the role of an opiate mechanism in this form of phasic hypoalgesia. In light of these findings, the present investigation explores whether reliable differences can be found between patients with asymptomatic and symptomatic myocardial ischaemia following injection of naloxone or placebo on experimentally determined pain thresholds and plasma beta-endorphins before, during and after physical exercise.

\section{Method}

ETHICAL APPROVAL

The study was approved by the ethical board of the Rehabilitation Centre in Bad Krozingen. At least 


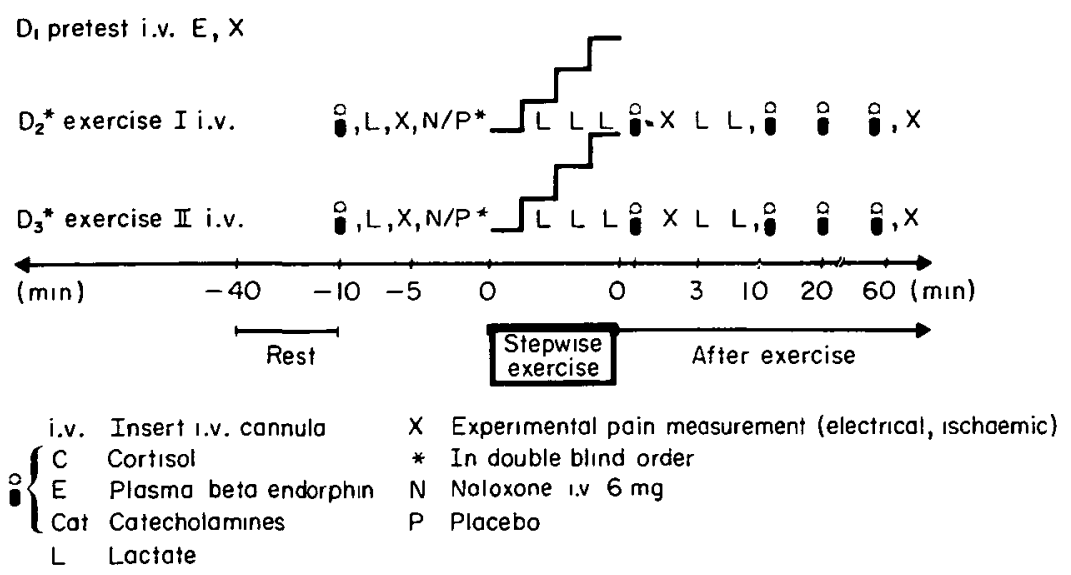

Figure I A schematic representation of the experimental design and time course of the measurements made.

one day before participating in the experiments, all patients were given a written explanation of the general research aims and possible hazards involved and were then requested to sign an informed consent, which was complicd with in all cases.

\section{PATIENTS}

A total of 17 men (mean age, $54 \pm 7$ years) with angiographically proved coronary artery disease were studied. All patients exhibited at least $75 \%$ stenosis in at least one major coronary artery, all of whom repeatedly demonstrated significant myocardial ischaemia ( $>0.1 \mathrm{mV}$ ST segment depression) in several exercise tests. A tolal of seven had already suffered an infarction. Eight patients exhibited symptomatic myocardial ischacmia (i.e.. concomitant occurrence of angina pectoris and ST segment depression during exercise tests). These latter patients also reported the occurrence of angina pectoris during their everyday life whenever they failed to take medication. The other nine patients had asymptomatic myocardial ischaemia, which was indicated by the absence of angina pectoris pain in the presence of ST segment depression during several exercise tests. Seven of nine patients reported an absence of angina pectoris in everyday life despite severe ischaemia evident in $24 \mathrm{~h}$ Holter monitoring. The other two patients reported only mild complaints. Patients were excluded who had any secondary diseases which could affect pain sensibility (e.g.. polyneuropathy. diabetes, alcohol addiction). In none of the patients had aortocoronary bypass surgery or percutaneous transluminal coronary angioplasty been performed. Symptomatic and asymptomatic patients did not differ in vessel disease. (symptomatic group: two with one-vessel disease, five with two-vessel discase, onc with three-vessel diseasc and the asymptomatic group: one, four, and four, respectively) or in left ventricular function (ejection fraction; $58+5.73$ symptomatic, $65+4.27$ asymptomatic patients).

\section{PROCEDURE}

The study consisted of three examinations conducted on separate days but always in the morning hours to control the possible effect of circadian rhythms. First, a pretest when resting was performed to determine pain thresholds and plasma betaendorphin levels. The pretest also served to allow the patients to become accustomed to the laboratory setting and the measurement procedure. The second and third examinations were conducted in a strict double-blind manner, where patients received either $6 \mathrm{mg}$ naloxone or saline $5 \mathrm{~min}$ prior to the start of exercise. Figure I describes the time course of the investigation. Prior to the experıments. all medication was withdrawn for a time period at least equal to five times the medication's half-life.

\section{PHYSICAL EXERCISE}

Physical exercise was performed supine using a commercially available bicycle ergometer (Elema Schönander). A 12-channel ECG was continuously registered. All patients commenced exercise at $50 \mathrm{~W}$. which was increased stepwise in 3-min segments each. Generally three or four exercise segments were performed. The criteria for termination of exercise was angina pectoris pain no longer tolerable by the patient. exhaustion or attainment of a max. $0.4 \mathrm{mV} \mathrm{ST}$ segment depression. 
BLOOD PLASMA DETERMINATIONS AND NALOXONE VS. PLACEBO

Blood was sampled using an intravenous cannula in the cubital vein in the nonpreferred arm, which was kept open with a slowly flowing saline solution. The first blood sample was taken 30 minutes after insertion of the cannula. During these $30 \mathrm{~min}$ the patient was requested to remain lying down and rest (Fig. 1). Blood samples were taken $10 \mathrm{~min}$ prior to exercise, at the point of maximal exertion, as well as 10,20 and $60 \mathrm{~min}$ following termination of exercise. Lactate was determined at each exercise level from blood drawn from the ear lobe. Naloxone (Narcan, DuPont Pharmaceuticals, $6 \mathrm{mg}$ in $15 \mathrm{ml}$ solution) and placebo ( $15 \mathrm{ml} 0.9 \%$ saline) were injected i.v. in random order under strict double-blind control $5 \mathrm{~min}$ prior to the start of exercise. With intravenous injection of naloxone, the full effect is immediately present and has a half-life of approximately 60 $\min ^{[10]}$. It can thus be assumed that at the time of exercise the effect of naloxone was substantial. Blood samples were drawn using chilled cannulas and were transported in ice and centrifugated at $+4^{\circ} \mathrm{C}$. Plasma was frozen at $-80^{\circ} \mathrm{C}$. Care was taken to assure that no more than $5 \mathrm{~min}$ elapsed between the time the sample was drawn from the vein and the start of centrifugation. Plasma beta-endorphins were determined using a highly specific radioenzymatic kit (Allegro, Nichols Institute, U.S.A.). The sensitivity of the assay is $10 \mathrm{pg} / \mathrm{ml}$. Cross reactivity to human beta-endorphin is $100 \%$, to other substances very low (human beta lipotropin 16\%, all others $<0.03 \%$ ). The intra-assay variation coefficient is $4.1 \%$, interassay variance $9 \%$. Samples were tested twice to control reliability, using the same kit for all samples from the same patient to eliminate variance across kits. Cortisol was determined via florescence polarization immunoassay (Abbott TDx Cortisol). Eplnephrine and norepinephrine were determined using high-performance liquid chromatography (HPLC-kit BIO-RAD).

\section{EXPERIMENTAL PAIN THRESHOLDS}

Electrical pain thresholds were determined prior to and directly after exercise, as well as $60 \mathrm{~min}$ following termination of exercise. An intracutaneous stainless steel electrode was inserted into the tip of the middle finger of the nonpreferred hand. Following the procedure described by Bromm and coworkers ${ }^{[1 I}$ we first removed $1-2 \mathrm{~mm}$ of the dermis with a manually operated dental drill. This reduced the skin resistance substantially. The stimulus was delivered via a specially designed electrical-stimulus generator under computer control using a two-interval forced-choice technique ${ }^{[12]}$. A $10 \mathrm{~ms}$ constantcurrent rectangular-wave impulse was presented randomly in one of two temporal intervals delineated by acoustic tones. The patients responded by pressing one of two buttons whether they thought the stimulus was presented in the first or second interval. Depending on whether the response was right or wrong, stimulus amplitude was reduced or increased based on a maximum likelihood threshold search algorithm (the best PEST ${ }^{[131}$ ). A threshold estimate was obtained after 40 trials and the $75 \%$ correctresponse level on the estimated psychometric function was the criterion used for the threshold.

We used a modified form of the tourniquet pain test ${ }^{[14]}$ to measure ischaemic pain threshold levels in the forearm. A manometer cuff was inflated to $200 \mathrm{mmHg}$ on the upper preferred arm to occlude bloodflow. Patients then engaged in a hand-grip exercise $(50 \%$ of maximal effort, which was determined using a Vigorimeter) at a predefined frequency of 40 depressions/min. To assess quantitatively the extent of ischaemia in the forearm, we measured simultaneously the transcutaneous partial oxygen tension $\left(\mathrm{IcPO}_{2}\right)$ polarographically using the Oxymonitor (cf. Hellige ${ }^{[5]}$ ). $\mathrm{Tc} \mathrm{PO}_{2}$ gives an estimate of the arterial $\mathrm{PO}_{2}$ and thus can be used as a correlate of tissue ischaemia. While the patients engaged in the hand-grip exercise they reported when they first experienced pain in the working arm (threshold) and when their point of subjective tolerance to the induced pain (tolerance level) was reached.

\section{CLINICAL PAIN MEASUREMENT}

The investigation was conducted in a quiet, shieldedoff room to avoid any possible source of distraction. All instructions were given by reciting a standardized text and talking was prohibited during measurements. The patient was requested to report whenever he felt any angina pectoris and if the severity of angina increased. The point in time of angina onset and increment was recorded using a series of stopwatches.

\section{Results}

For all patients exercise was so intense that the maximal lactate levels exceeded in all cases the anaerobic threshold of $4 \mathrm{~mm}^{-1}$. No differences in the extent and duration of exercise was found between symptomatic and asymptomatic patient groups nor between naloxone vs. placebo conditions (cf. Table 1). Furthermore, no significant group differences 
Table I Compartson of exercise parameters, lactate levels and electrocardiographic variables in symptomatic ( $\mathrm{N}=8$ ) and as 'mptomatic $(\mathrm{N}=9)$ patients following placebo and $6 \mathrm{mg}$ naloxone

\begin{tabular}{|c|c|c|c|c|c|c|c|c|}
\hline & \multirow{2}{*}{$\begin{array}{l}\text { Max. } \\
\text { exercise } \\
\text { (W) }\end{array}$} & \multirow{2}{*}{$\begin{array}{l}\text { Duration } \\
\text { of exercise } \\
\text { (s) }\end{array}$} & \multirow{2}{*}{$\begin{array}{c}\text { Max. } \\
\text { Lactate } \\
\left(\mathrm{mMl}^{-1} \mathrm{I}\right)\end{array}$} & \multirow{2}{*}{$\begin{array}{l}\text { Max. } \\
\text { ST-1 } \\
(\mathrm{mV})\end{array}$} & \multirow{2}{*}{$\begin{array}{c}\text { Max. } \\
\text { Heart rate } \\
\text { (beats } \mathrm{min}^{-1} \text { ) }\end{array}$} & \multicolumn{2}{|c|}{$\begin{array}{l}\text { Max. blood } \\
\text { pressure }\end{array}$} & \multirow{2}{*}{$\begin{array}{c}\text { Max. } \\
\text { double } \\
\text { product } \\
\text { HF } \times \text { RRs }\end{array}$} \\
\hline & & & & & & Syst. & Diast. & \\
\hline \multicolumn{9}{|c|}{ Symptomatic patients $(N=8)$} \\
\hline Placebo & $116 \pm 27$ & $529 \pm 202$ & $5-97 \pm 2 \cdot 25$ & $0.26 \pm 0.11$ & $123 \pm 24$ & $193 \pm 29$ & $105 \pm 9$ & $23968 \pm 7387$ \\
\hline Naloxone & $119 \pm 22$ & $539 \pm 200$ & $6 \cdot 22 \pm 2 \cdot 87$ & $0.24 \pm 0.10$ & $122 \pm 20$ & $193 \pm 23$ & $104 \pm 8$ & $23734 \pm 5766$ \\
\hline \multicolumn{9}{|c|}{ Asymptomatic Patients $(N=9)$} \\
\hline Placebo & $125 \pm 35$ & $487 \pm 186$ & $7 \cdot 17 \pm 1 \cdot 80$ & $0.29 \pm 0.15$ & $128 \pm 15$ & $184 \pm 15$ & $104 \pm 11$ & $23719 \pm 4323$ \\
\hline Naloxone & $122 \pm 34$ & $470 \pm 192$ & $6 \cdot 84 \pm 1 \cdot 70$ & $0.28 \pm 014$ & $130 \pm 13$ & $182 \pm 14$ & $104 \pm 9$ & $23695 \pm 3335$ \\
\hline
\end{tabular}

were found for maximal lactate level, maximal ST segment depression, maximal heart rate, maximal systolic and diastolic blood pressure or maximal double product.

\section{PLASMA BETA-ENDORPHIN LEVELS}

No significant differences were found between symptomatic and asymptomatic patients on betaendorphin levels in plasma during rest. The pretest (day 1) beta-endorphin resting values were in all patients higher than on days 2 and 3 , which was probably a result of unspecific activation in the new test situation. Asymptomatic patients exhibited slightly higher values than did symptomatic patients on day 1 . On days 2 and 3 the resting values, measured after $30 \mathrm{~min}$ of rest, did not differ noticeably between patient groups (maximal difference $<8 \%$ ). Plasma beta-endorphin levels increased significantly during exercise in both symptomatic and asymptomatic patient groups (Fig. 2). The maximal betaendorphin level was usually reached $10 \mathrm{~min}$ following cessation of exercise. Original baseline levels were usually obtained $60 \mathrm{~min}$ following exercise. An analysis of the individual time course for each patient indicated that every patient demonstrated an increase in beta-endorphins during and after exercise. In the symptomatic group, the mean increase in beta-endorphin levels was $37 \%$ of the baseline level $(P<0.01)$. Asymptomatic patients exhibited a significantly larger increase in beta-endorphins: at maximal exertion the increase is $141 \%$ above baseline levels, and $212 \%$ above baseline $10 \mathrm{~min}$ after exercise cessation. Twenty minutes after exercise a $158 \%$ increase was still evident and $60 \mathrm{~min}$ following exercise betaendorphin levels were still increased. This exerciseinduced increase in beta-endorphins is highly significant $(P<0.0001)$ in the asymptomatic patients.
The most important result here is that beta-endorphin levels differ significantly $(P<0.01)$ between symptomatic and asymptomatic patients at the point of maximal exertion, $10 \mathrm{~min}$ and 20 minutes after exercise cessation.

\section{EFFECT OF NALOXONE}

After naloxone injection, significant differences were no longer found between symptomatic and asymptomatic patients on the exercise-induced increase in beta-endorphin levels (Fig. 2). In both patient groups, the $6 \mathrm{mg}$ injection of naloxone evoked an increment in the serum beta-endorphin levels. This exercise-induced increase in beta-endorphins after naloxone was larger in the symptomatic patients and thus nullified the group differences found under placebo.

\section{Plasma CORTISOl Levels}

The time course of plasma cortisol levels exhibited the same pattern as beta-endorphins with a $10 \mathrm{~min}$ time lag, suggesting a common excretion of both ACTH as a precursor of cortisol and beta-endorphins from the hypophysis. Following placebo control injection, a significant difference is evident between symptomatic and asymptomatic patients on cortisol levels, and this difference is nullified by naloxone (Fig. 2, lower panel). No group differences were evident on catecholamine levels nor between placebo and naloxone conditions. Values increased uniformly in both groups during exercise.

\section{ANGINA PECTORIS PAIN DURING EXERCISE}

After $6 \mathrm{mg}$ naloxone i.v. prior to exercise, seven of eight symptomatic patients reported the occurrence of angina pectoris with less delay with respect to the onset of ST segment depression during exercise than 

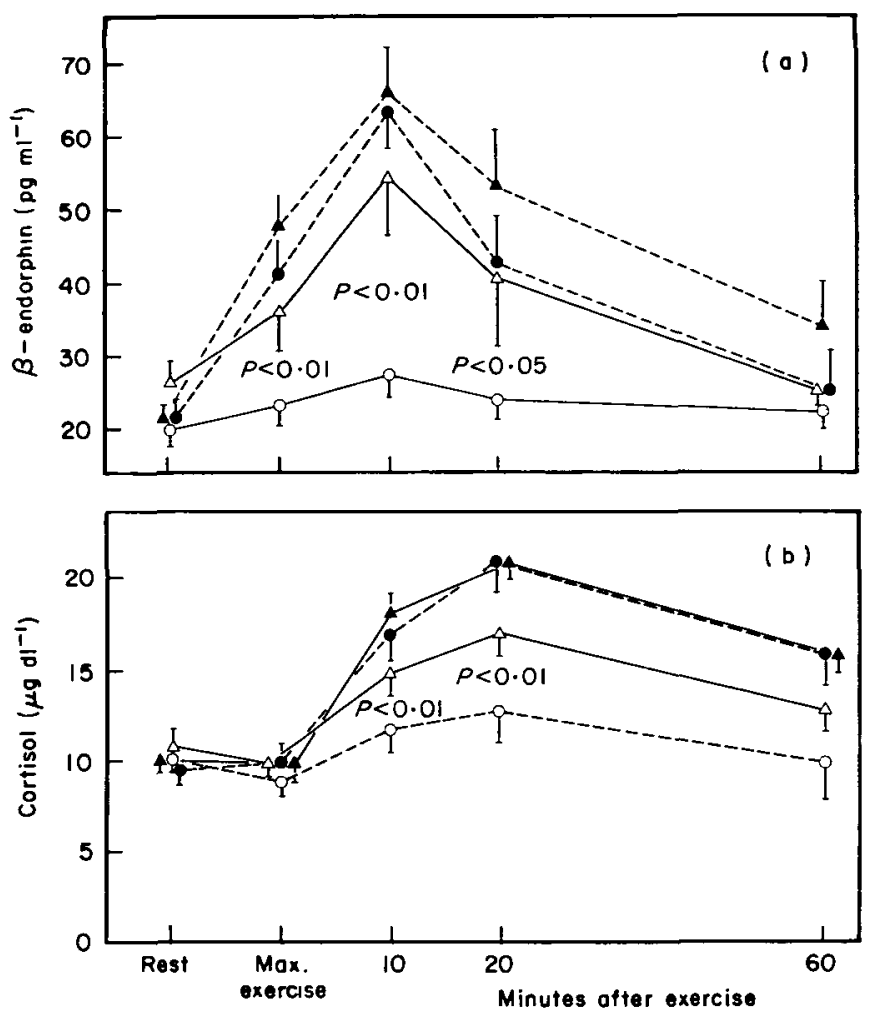

Figure 2 Comparison of (a) plasma beta-endorphin levels and (b) cortisol in symptomatic $(O, 0)$ and asymptomatic $(\boldsymbol{\Delta}, \Delta)$ patients following placebo $(O, \Delta)$ and naloxone $(\boldsymbol{O} . \Delta)$. Error bars show \pm 1 $\mathrm{SD}$ of the mean.

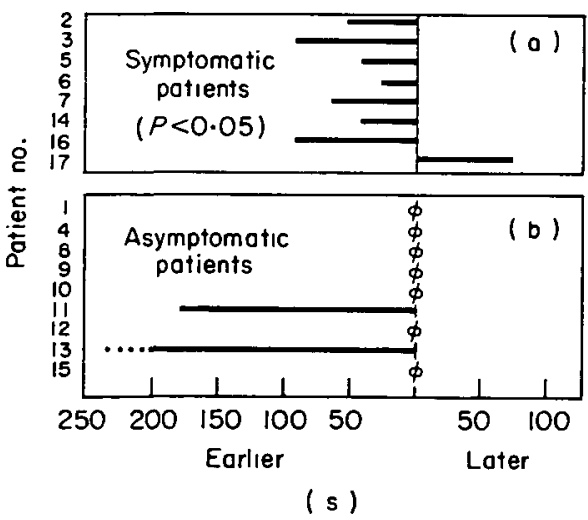

Figure 3 The effect of naloxone on the onset of angina pectoris pain during exercise in (a) symptomatic and (b) asymptomatuc patients.

following placebo $(P<0.05)$. The time differences are shown in Fig. 3. The total duration of angina pectoris was prolonged after naloxone compared to placebo ( $405 \pm 148$ vs. $333 \pm 97$ s, respectively). More time was required after termination of exercise in the naloxone condition before patients were relieved of angina pectoris $(686 \pm 171 \mathrm{~s}$ vs. $658 \pm 181 \mathrm{~s}$, respectively), although these differences were not significant.

In the naloxone condition, two asymptomatic patients, who had never before experienced angina pectoris during ST segment depression under exercise, reported typical angina pectoris symptoms. The severity of their discomfort and the magnitude of the ST segment depression in these two patients was such that exercise did not need to be prematurely terminated. One of these patients reported occasional occurrences of angina pectoris during everyday life, whereas the other was completely free of subjective symptoms. Angina pectoris could not be provoked in the other seven asymptomatic patients after $6 \mathrm{mg}$ naloxone injection.

\section{EXPERIMENTAL PAIN THRESHOLDS}

Ischaemic pain thresholds significantly differed between symptomatic and asymptomatic patients [Fig. 4(a)]. Symptomatic patients reported having 

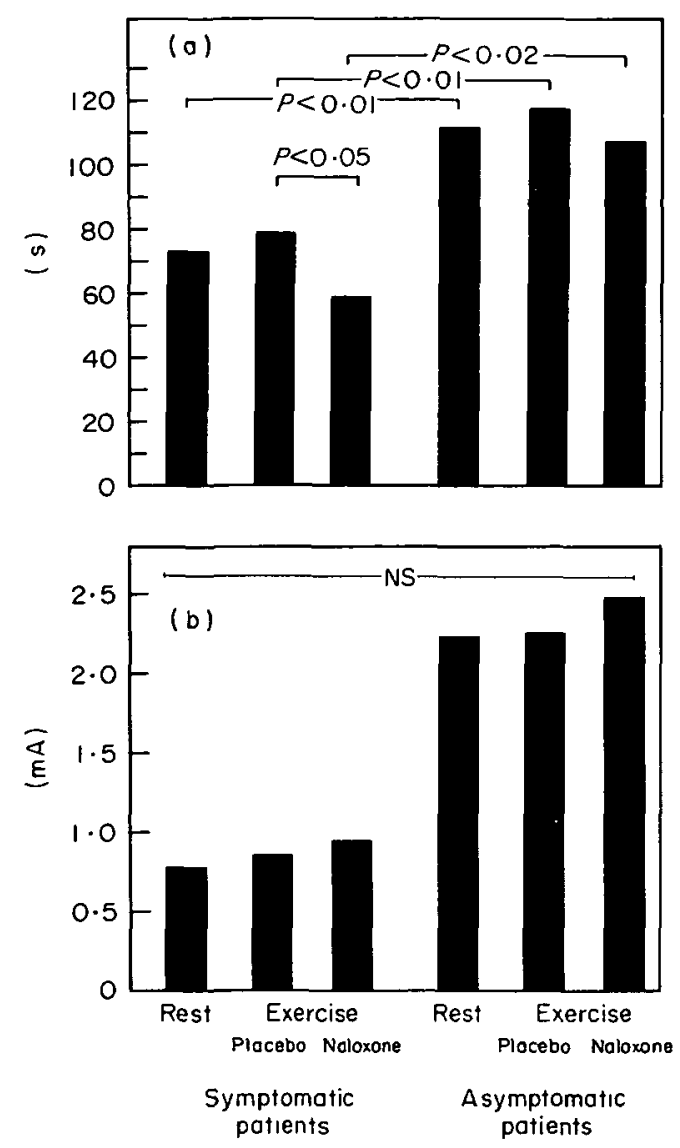

Figure 4 Comparison of (a) ischaemic and (b) electrical pain tests in symptomatic and asymptomatic patients.

pain $73.8 \mathrm{~s}$, on average, following cuff inflation and the start of excrcise, whereas asymptomatic patients required a mean of $112.1 \mathrm{sec}$ before they felt pain. This difference is highly significant $(P<0.01)$ and corresponds well with the findings of our earlier study ${ }^{[16.17]}$. A moderate, but not significant, increase in ischaemic pain thresholds was found after exercise. Following naloxone injection and after exercise, asymptomatic (109.8s) and especially symptomatic $(59.1 \mathrm{~s})$ patients required less time to reach ischaemic pain thresholds. Compared with the placebo condition, this difference was significant $(P<0.02)$. These differences were especially noticeable in the two asymptomatic patients who reported angina pectoris during exercise following naloxone.

Asymptomatic patients exhibited substantially higher electrical pain thresholds at rest $(2.213 \mathrm{~mA})$ compared with their symptomatic counterparts [0.793 mA; Fig. 4(b)]. Due to large inter-individual differences and the small sample size, this difference did not, however, obtain traditional significance levels. An exercise-induced elevation in pain threshold was not evident. Directly after exercise, symptomatic patients had a mean threshold of $0.865 \mathrm{~mA}$ and the asymptomatic patients a mean threshold of $2.237 \mathrm{~mA}$. Naloxone did not have a significant effect on electrical pain thresholds.

\section{Discussion}

One of the major findings of the present investigation indicates that during exercise asymptomatic patients exhibit significantly greater clevations in beta-endorphins in plasma than do symptomatic patients. Following injection of $6 \mathrm{mg}$ naloxone this difference is reduced and no longer statistically significant. This finding suggests that excretion of circulating beta-endorphins from the hypophysis is regulated by an opioid mechanism and that there are quantitative differences in this opiold control between symptomatic and asymptomatic patients. The opioid regulation of ACTH as a precursor of cortisol has been demonstrated ${ }^{[18]}$. It appears that ACTH and beta-endorphins are produced in parallel and that naloxone may affect corticotropic releasing factors $^{[19]}$

The finding that beta-endorphin levels are greater during exercise in asymptomatic patients suggests, at first glance, that circulating endorphins have a direct effect on pain thresholds. The results of earlier studies, however, indicate that such a direct relationship is probably not the case. There are, for example, disorders where the beta-endorphin levels are greatly elevated (e.g. in the Nelson syndrome with levels ranging from $400-700 \mathrm{pg} \mathrm{ml}^{-1}$ ), but pain thresholds are normal. On the other hand, there are cases reported where the patients have extreme congenital hypoalgesia but beta-endorphin levels are normal, although naloxone can reverse these elevated pain thresholds ${ }^{[7]}$. Intravenous injection of beta-endorphins does not have an analgesic effect, even when given in high doses, although an analgesic effect has been found after beta-endorphin injection in cerebral spinal fluid ${ }^{21]}$. The site of beta-endorphinergic action appears thus most likely to be in the central nervous system and not in the periphery. Owing to their high molecular weight, beta-endorphins cannot pass the blood-brain barrier. It is assumed, however, that excretion of beta-endorphins by the hypophysis and changes in central-nervous beta-endorphin levels are positively correlated ${ }^{(22)}$.

Although a direct effect of beta-endorphins in 
serum on pain regulation is not to be expected, we assume that a complex. opioid-based pain regulatory mechanism is involved in the presence or absence of coronary pain. It should be noted that our asymptomatic and symptomatic patients differ only in one major way, namely the presence or absence of pain during adequate stimulation. Table 1 indicates that the extent of myocardial ischaemia. as well as the extent of physical exercise reached during testing do not differ between patient groups and thus cannot explain the lack of pain in asymptomatic patients. An analysis of each individual time course indicated that beta-endorphin levels increased during exercise in every patient and then returned to normal in resting. Exercise at approximately $100 \mathrm{~W}$ is sufficient to provoke an increase in beta-endorphins. Thus typical exercise tests in coronary patients should be sufficiently strenuous to elicit changes in circulating beta-endorphins.

It is well known that serum beta-endorphin levels can be influenced by several factors. We found that a prolonged restung period at the beginning of the measurement session, as well as a pretest to let the patients accommodate themselves to the experimental setting and measurements, is required to obtain reliable basal values. We also observed that differences in beta-endorphin determinations can occur depending on whether the blood-sample cannula is chilled or not and whether the blood is immediately centrifugated and chilled during centrifugation or whether some time elapses between the time of blood sampling and centrifugation. There are also differences between the various determination methods; some kits cxhibit a high cross-reaction with other proteins and thus lead to higher values than normally found ${ }^{[23]}$.

The method of beta-endorphin determination used in the present study exhibits a very low cross-reaction and the rest values measured in our patients correspond well with those in the literature ${ }^{(24)}$. The analysis of each patient's values indicated that, compared with the symptomatic patients, eight of the nine asymptomatic patients tested exhibited a greater increase in beta-endorphins during exercise. These differences were nullified by naloxone. The significant differences between asymptomatic and symptomatic patients on cortisol suggest that these patients differ with respect to neuroendocrine regulation.

Earlier studies concerned with the possible role of endogenous opiates in silent myocardial ischaemia have brought forth, in part, contradictory results. In addition to the possible methodological flaws discussed above, the following aspects may be important factors with respect to the disparate findings: (1) most of these studies have tested either symptomatic $^{[25.29]}$ or asymptomatic patients ${ }^{[17.23 .27]}$ and (2) they have either been limited to the determination of plasma beta-endorphins ${ }^{[28-30]}$ or to naloxone injection ${ }^{[17.25-27]}$ but not both. The only study[23]. besides the present one. that has combined these measurements used a relatively unspecific determination technique (yielding resting values 10 times higher than normal) and found no increase in circulatung beta-endorphins during exercise. Our results are in good agreement with the recent work of Specchia and his coworkers ${ }^{28]}$, who also found significant differences in beta-endorphin levels in symptomatic and asymptomatic patients, and differences in experimentally determined pain thresholds ${ }^{[31]}$. These authors found differences already in resting betaendorphin levels, which may be related to higher arousal levels in these patients during testing. The beta-endorphin levels we found on day 1 during the pretest, where the patients did not rest for $30 \mathrm{~min}$ prior to blood sampling, also show a tendency to be higher in the asymptomatic patients.

Another important factor causing the contradictory results apparent in the literature is the criterion used to assign patients into symptomatic and asymptomatic groups. As in our carlier studies ${ }^{[17.32)}$, we have sclected asymptomatic patients based on the strict criterion that they had never before reported angina pectorıs pain during exercise testing. Only two of our nine asymptomatic patients reported any discomfort during everyday life. Our asymptomatic patients also exhibit extremely high experimentally determined pain thresholds, which would presumably not be the case had we selected patients with less pronounced asymptomatic myocardial ischaemia. The same line of reasoning may also hold for the betaendorphin differences found here. Since we selected extreme patient types with respect to the occurrence or absence of angina pectoris during exercise, the patient groups exhibit significant differences, which might not be as clearcut in patients with a mixed form of myocardial ischaemia having both silent and painful ischaemic episodes.

A possible explanation for the group differences on beta-endorphins found here would be that the differences on endorphin levels are not the cause of the absence of pain in myocardial ischaemia, but rather that these differences are the consequence of the presence or absence of chronic pain in these patients. There are a number of studies in the literature which indicate that prolonged chronic pain is associated with a reduction in the beta-endorphin 
level in cerebrospinal fluid ${ }^{[33.34]}$. The extent to which secretion of beta-endorphins in serum is related to changes in the CSF level of beta-endorphins has still to be determined. All of our symptomatic patients had a long history of angina pectoris pain having several painful episodes each week for several years. It could be speculated that such prolonged pain could lead to a fatiguing of the endorphinergic system and thus to a lower rate of release or to an increased rate of metabolism. If this is the case then the question arises why such a regulative mechanism does not affect the sensibility of all patients with myocardial ischaemıa, and why asymptomatic patients appear to be an exception to the general rule. A possible factor may be found in the earlier clinical history of the patient, where some patients experience intense chronic pain and others suppress painful episodes. If the lower reactivity of endorphinergic mechanisms to physical exercise in symptomatic patients found here is related to a prolonged history of pain, then such a difference appears to be reversible by naloxone, a finding which has not yet been reported in the literature.

Agonist-induced receptor down-regulation has been shown to affect the density of adrenergic receptors. It could be presumed that opioid receptors may also increase their density depending on the level of opioids ${ }^{|35|}$. Thus it could be argued that symptomatic and asymptomatic patients may differ with respect to the density of opioid receptors involved in the mediation or blockıng of nociceptive afferents from the myocardium. Unfortunately, there is, to our knowledge, at present no sufficient evidence in the literature to support such speculation.

The experimental pain thresholds reported here support our earlier findings ${ }^{\{16.32\}}$ and those of other research groups ${ }^{[31.36]}$, namely that asymptomatic patients exhibit higher pain thresholds than do symptomatic patients, although there is considerable within-group variance. The finding that naloxone had an effect on ischaemic pain thresholds but not on electrical pain thresholds corresponds to the findings of earlier investigations ${ }^{[9]}$. Our $6 \mathrm{mg}$ injection of naloxone had an effect. though just barely significant. on the latency of angina pectoris onset. Our experimental control in this respect, using a series of stopwatches and a quiet recording environment, led to reproducible results. Despite these precautions, the effect of $6 \mathrm{mg}$ naloxone was small, which may suggest that larger doses are required or that nonopioid receptors are involved and that naloxone does not block specifically enough. Contrary to the result expected on the basis of an earlier study ${ }^{[37]}$, naloxone had no effect on catecholamines levels during exercise, which would have increased oxygen consumption, and thus could have led to group differences between placebo and naloxone conditions.

In summary, the findings of the present investigation suggest a possible role for an endorphinergic mechanism in the control of myocardial ischaemic pain, although other mechanisms are surely involved. The greater increase in circulating endorphins found here in exercising asymptomatic patients may not be, in itself, the cause of their lacking angina pectoris pain, but rather reflects a higher reactibility of opioid mechanisms to stressful stimuli. These differences between symptomatic and asymptomatic patients are reversed by naloxone, thus pointıng to quantitative differences in the opioid regulation of pain in these patient groups.

This research was supported by the Deutsche Forschungsgemeinschaft (SPP II B7- Dr $190(1-1)$ ) to C. Droste. M. W. Greenlee was supported by the SFB 325, B4 The authors thank Frau G. Clauberg for her assistance during the expermments.

\section{References}

[1] Fields HL Neurophysiology of pain and pain modulation. Am J Med 1984; 78' 2-8.

[2] Mayer DJ. Watkins LR. Multiple endogenous opiate and nonopiate analgesıa systems. In: Kruger $\mathrm{L}$ and Llebeskind JC, eds. Advances in pain research and therapy, 1984: In Kruger L, Liebeskind JC (eds) Advances in pain research and therapy, Vol. 6, New York: Raven Press. 1984, 523.

[3] Kemppainen P. Pertovaara A. Huopaniemi T. Johansson G. Karonen SL. Modification of dental pain and cutaneous thermal sensituvity by physical exercise in man. Brain Res 1985; 360: 33-40.

[4] Olausson B, Enksson E. Ellmarker L Rydenhag B, Shyu BC. Andersson SA. Effects of naloxone on dental pain threshold following muscle exercise and low frequency transcutaneous nerve stımulation: a comparative study. Acta Physiol Scand, 1986: 126: 299-305.

[5] Arentz R. de Meirleir K. Hollmann W. Die Rolle der endogenen opioiden Peptide während Fahrradergometerarbeit. Disch Z Sportmed. 1986: 37: 210-9.

[6] Shyu BC. Andersson SA. Thoren P. Endorphin mediated increase in pain threshold induced by long lasting exercise in rats. Life Sci 1982: 30 833-40.

[7] Willer JC et al. Pituitary beta-endorphin not involved in pain control in some pathophysiological conditions. Lancet 1984: 8397: $295-6$.

[8] Haier RJ. Quaid K. Mills JSC. Naloxone alters pain perception after jogging. Psychiat R, 1981: 5: 23I-2.

[9] Janal MN. Cold EWD. Clark WC. Glusman M. Pain senstivity, mood, and plasma endocrine levels in man following long-distance running: effects of naloxone. Pain 1984: 19: 13-25. 
[10] Misra AL. Metabolism of opiates. In: Adler M, Manara L. Samanin R. eds. Factors affecting the action of narcotics. New York Raven Press, 1978: 297343.

[11] Bromm B, Meter W. The intracutaneous stimulus: a new pain model for algesimetric studies. Meth Find Exp Clin Pharmocol, 1984: 6: 405-10.

[12] Green DM. Swets JA. Signal detection theory and psychophysics. New York: Wiley. 1966.

[13] Lieberman HR, Pentland AP. Microcomputer-based estimation of psychophysical thresholds: The best PEST. Behav Res Meth Instrum 1982; 14: 21-5.

[14] Moore PA, Duncan GH, Scott DS, Gregg JM. Ghia JN. The submaximal effort tourniquet test: its use in evaluatung experimental and chronic pain. Pain, 1979; 6: $375-82$.

[15] Droste C, Greenlee MW. Two separate components of pain produced by the submaximal effort tournıquet technique. Pain 1985: 23: 95-6.

[16] Droste C, Roskamm H. Experimental pain measurement in patients with asymptomatic myocardial ischemia. JACC. 1983: 1: 940-5.

[17] Droste C, Roskamm H. Pain measurement and pain modification by naloxone in patients with asymptomatic myocardial ischemia In: Rutishauser W, Roskamm H, eds. Silent myocardial ischemia. Berlin; Springer, 1984: 14-23.

[18] Gullemin R, Vargo T, Rossier J, et al. $\beta$-endorphin and adrenocortiglandin are secreted concomitantly by the pituitary gland. Science, 1977, 197: 1367.

[19] Petraglıa F. Facchinetti F, Parrını D, Micieli G, de Luca S, Genazzani, AR. Simultaneous circadian variations of plasma ACTH, beta-lipotropin, betaendorphın and cortisol Hormone Res 1983: 17 14752.

[20] Volavka J, James B, Reker D. Pollock V, Cho D. Electroencephalographic and other effects of naloxone in normal men. Life Sci 1979; 25: 1267-72.

[21] Loh $\mathrm{HH}, \mathrm{LiCH}$. Bılogic actıvities of $\beta$-endorphin and Its related peptides. Ann NY Acad Sci 1977; 297: 115 30.

[22] Page RB, Munger BL, Bergland RM. Scanning microscopy of pituitary vascular casts. Am J Anat 1976; 146: 273-301.

[23] Weidinger F, Hammerle A, Sochor H. Smetana R, Frass $M$, Glogar D. Role of beta-endorphins in silent myocardial ischemia. Am J Cardiol 1986; 58: 428-30.

[24] Cox BM and Baizman ER. Physıological functions of endorphins. In: Malick JB. Bell BMS, eds. Endorphins. New York: Marcel Dekker, 1982: 113-96.

[25] Van Rijn T, Rabkın SW. Effect of naloxone on exercise-induced angina pectoris: a randomized doubleblind crossover trial Life Sci, 1986; 38: 609-15.

[26] Cohn PF, Patcha R, Singh S. Studies on the pathophysiology of silent myocardial ischemia: effect of naloxone on pain threshold during exercise tests. Clin Res 1985; 33: 177A (Abst).

[27] Ellestad MH, Kuan P. Naloxone and asymptomatic 1schemia: Failure to induce angina during exercise testing. Am J Cardiol 1984; 54: 982-4.

[28] Falcone C, Ochan M, Codega S, Melchiorre P, Rondanelli R, Specchia G. Correlation between betaendorphin plasma levels and anginal symptoms in patients with coronary artery disease JACC 1988; 11 : 719-23.

[29] Sheps DS, Adams KF, Hinderliter A, el al. Endorphins are related to pain perception in coronary artery disease. Am J Cardiol 1987; 59: 523-7.

[30] Heller GV, Ewing GC, Connolly MJ, et al. Plasma beta-endorphin levels in silent myocardial ischemia induced by exercise. Am J Cardiol 1987; 59: 735-9.

[31] Falcone C, Guasti L, Codega S, de Servi S, Ghio S, Specchia G. Pain threshold in patients with coronary artery disease. JACC 1988 (in press).

[32] Droste C, Greenlee MW, Roskamm H. A defective angina pectors pain warning system: experimental findings of ischemic and electrical pain test. Paın 1986; 26: 199-209.

[33] Terenius L. Endorphins and modulation of pain. Adv Neurol 1982: 33: 59-64.

[34] Almay BGL, Johansson F, von Knorring L, Terenius L. Wahlström A. Endorphins in chronic pain. I. Differences in CSF endorphin levels between organic and psychogenic pain syndromes. Pain 1978; 5: 153-162.

[35] Cox BM, Ross M, Goldstein R, Palmour R. Pharmacological and immunological characterization of the LEU analogue of human $\beta$-endorphin. Brain Res, 1979; 165: 311-9.

[36] Glazier JJ, Chierchia S, Brown MJ, Maserı A. Importance of generalized defective perception of painful stumuli as a cause of silent myocardial ischemia in chronic stable angina pectoris. Am J Cardiol 1986; 58 : 667-72.

[37] Grossman A. Bouloux P, Price P, el al. The role of opioid peptides in the hormonal response to acute exercise in man. Clin Sci 1984; 67: 483-91. 